\title{
Positive and Negative Syndrome Scale Clinical Classification
}

National Cancer Institute

\section{Source}

National Cancer Institute. Positive and Negative Syndrome Scale Clinical Classification.

NCI Thesaurus. Code C124712.

A standardized rating scale developed by Kay et al in 1987, which is a classification system used to measure severity of patients with schizophrenia. This instrument rates a patient on a scale of 1 (absent) to 7 (extreme) on 30 different symptoms. 